\title{
Global oral health course: Perception among dental students in central India
}

Abhinav Singh ${ }^{1}$

Bharathi Purohit ${ }^{2}$

\begin{abstract}
A questionnaire study was conducted among dental students in Central India. The study population included 264 dental students, who voluntarily completed a questionnaire, comprising of 16 close ended questions. There were 9 questions to judge knowledge and 5 questions for attitude assessment towards global oral health course. Two additional questions were included to assess the willingness to volunteer in international setting; and also, to assess dental student's perspection on global oral health course. Chi Square test was used to compare between categorical variables. Analysis of Variance (ANOVA) was used to compare mean of knowledge and attitude scores. P value of $\leqslant .05$ was considered significant for all statistical analysis. Eighty seven percent of the surveyed students (222) stated that they would consider volunteering their dental skills as a future dentist in international setting. Majority of the students in the present study were not aware about the global oral health status $(99.2 \%)$ and theoral health care systems of industrialized and emerging economies $(99.2 \%)$, had not been trained to serve underserved population $(68 \%)$, had not been trained in global health ethics $(70.1 \%)$ and none of the students had been trained for cultural competence in addressing international oral health issues (100\%). Most of the dental students were not aware, that, WHO created basic package of oral care $(63 \%)$ about the primary health care strategy $(59.5 \%)$ and about the role and functions of FDI (66.7\%). The majority of students expressed a desire to volunteer their professional services in international settings. However few students knew about WHO's BPOC or FDI'S role in global oral health. The findings indicate a need for global oral health course among dental students in Central India. (Eur J Dent 2012;6:295-301)
\end{abstract}

Key words: Global oral health; primary oral health; pre doctoral dental education; dental volunteer

1 Department of Public Health Dentistry, ESIC Dental College \& Hospital, Rohini - New Delhi, Under Ministry of Labour \& Employment Government of INDIA

2 Department of Public Health Dentistry, People's College of Dental Sciences, Bhopal, INDIA

- Corresponding author: Dr. Abhinav Singh Department of Public Health Dentistry, ESIC Dental College \& Hospital, Rohini - New Delhi, Under Ministry of Labour \& Employment - Government of INDIA Email: drabhinav.singhagmail.com

\section{INTRODUCTION}

In spite of considerable investment in research and dental services, oral diseases are still a major global health burden. Noncommunicable chronic diseases, which continue to dominate in lowermiddle and upper income countries, are becoming increasingly prevalent in many of the emerging and least developed countries. Burden of diseases is doubled with the infectious diseases also continuing to afflict this countries. ${ }^{1}$ 
Dental caries is one of the most common chronic diseases worldwide leading to loss of millions of lost days of school days for children and absenteeism from work in adults, resulting in both short- and long-term impacts on economic productivity. ${ }^{2}$ This effect is most marked in lowand middle-income countries, where ineffective prevention and limited access to dental treatment means that much of the demand for care is not met. Severe periodontitis affects $5-20 \%$ of most adult populations worldwide, and it is a major cause of tooth loss both in industrialized and least developed countries. ${ }^{3-4}$ As with dental caries, there is a marked social class gradient in the distribution of periodontal disease. ${ }^{5}$ Oral cancer is the eighth most common cancer worldwide and the most common in men in Southeast Asia. ${ }^{6-7}$

Oral diseases also remain a major public health issue for high-income countries, where expenditure on treatment often exceeds that for other diseases, including major diseases such as cancer, heart disease, stroke, and dementia. However, statements about the differences in levels of disease at country level alone fail to reveal an even more important issue, namely, that major inequalities exist both within and between countries in terms of disease severity and prevalence. ${ }^{8}$

All of the above-mentioned issues raise important questions about what is to be done, and by whom. We still have a very long way to go in advocating effectively and implementing the potential improvements in oral health that are known to be achievable. Most importantly, the situation is unlikely to change without a transformation in our priorities together with recognizing that we need to work with other agencies. Tackling global oral health inequalities will require establishing a kind of workforce appropriate to a range of global settings, creativity, diligence and a strong commitment to partner with the many players involved in global health. ${ }^{9-10}$

Over the past few decades, there has been a strong international aid response to public health emergencies and oral health disparities in emerging economies and the least developed countries. ${ }^{11-12}$ Dental aid organizations and other nongovernmental organizations (NGOs) are important partners in global oral health development. Benzian and Gelbier in a study to collect basic data about non-governmental dental aid organisations on a global scale reported that about two thirds of NGOs originated in industrialized countries and one third responded from developing countries. The majority had been established after 1980.
The workforce was primarily based on volunteers; high priority activities included service provision, education and training, technical assistance, community development. Frequent areas of problems were associated with funding and staff. Collaborative links with other stakeholders in development were weak and focused on information exchange. ${ }^{13}$

Community service is not a formally recognized competency for a general dentist in various countries including North America. The revised competencies for the predoctoral dental school curriculum endorsed in March 2008 by the American Dental Education Association (ADEA) are intended to define the entry-level professional capacities of the general dentist. However, this document neither has any mention of community service, nor regarding provision of care to the underserved communities or populations under the domain of professionalism. ${ }^{14}$

Dental schools in high income countries have introduced a global oral health course though the numbers of such schools are limited. India has the highest number of dental institutions in the world. The number of dental professionals in India has increased from 60,000 to $1,75,000$ and is projected to be more than $3,00,000$ in the next five years. Each year more than 25,000 dental graduates are added to this list.15 Although, the number of dental institutions has also correspondingly increased from 120 to 289 in the past ten years, yet, none of the schools are running any course on global oral health or have introduced it into predoctoral dental curricula. Keeping this in mind the present study was conducted to analyze the awareness, content and need of global oral health course among dental students. Specifically, the aim of the study was to analyze dental student's perception towards global oral health course in Bhopal city, Central India.

\section{METHODS}

A questionnaire study was conducted among dental students (third year, final year, interns and residents or post graduate doctorsl of People's College of Dental Sciences, Bhopal city, Central India. The study population included 264 dental students who voluntarily completed a questionnaire comprising of 16 questions. The sample size comprised of 86 third year dental students, 77 final years, 75 interns and 26 resident students. Interns are graduates from the same school, with postings equally distributed in respective departments during the stipulated one year. The percentage of students in third year, final year, internship and 
residents who responded to the questionnaire was $91.5 \%, 91.1 \%, 89.5 \%$ and $94 \%$ respectively. Interns and residents were included in the study, so as to note, if any difference exists in perceptions towards global oral health course among residents, interns and undergraduates. The questionnaire was framed with the help of experts in the field. It was framed keeping the study group in mind and questions were linked to curriculum content of global oral health course as described by Karim et al (2008).

A self-administrated questionnaire consisting of 16 close-ended items was used for data collection. Third and final year dental students were distributed the questionnaire after a regularly scheduled lecture class. The interns and residents were given the same questionnaire in respective departments.

There were 9 questions to judge knowledge and 5 questions for attitude assessment towards global oral health course. Two additional questions were included to assess the willingness to volunteer in international setting, and also, to assess dental student's perspective on global oral health course.

Informed consent and institutional clearance were granted for the study. The questionnaire was pretested on a random sample of dental students to ensure practicability, validity and interpretation of responses. The validity of questionnaire was assessed using Cronbach's alpha internal consistency coefficient which was in range of 0.82 to 0.86 . Chi Square test was used to compare between categorical variables. Analysis of Variance (ANOVA) was used to compare mean of knowledge and attitude scores. $P$ value of $\leqslant .05$ was considered significant for all statistical analysis. Statistical analysis was performed using the Statistical Package for Social Sciences (SPSS) software for windows version 13

\section{RESULTS}

Of the 264 dental students, 106 were males and 158 females, gender differences being non significant. (Table1) Two hundred and twenty two (84\%) students stated that if asked they would volunteer as a dentist in an international setting or other emerging economies. Majority of the students were not aware about the global oral health status and oral health care systems of the industrialized and emerging economies (99.2\%). Majority of the students $(68 \%)$ also reported that they had not been trained to serve the underserved population. None of the students reported of having been trained for cultural competence in addressing international oral health issues. One hundred eighty five students $(70.1 \%)$ stated that they were not aware about the global health ethics. (Table 2)

Global oral health status information was considered essential by 194 (73.5\%) dental students to address international health issues. Two hundred and nine students $(79.2 \%)$ considered both information about oral health care systems in industrialized and emerging economies, and, training to serve underserved population, as essential, to address global oral health issues. Training in cultural competence was stated essential to address global oral health issues by 219 (83\%) dental students. Global health ethics awareness was affirmed as essential to address international oral health issues by majority of dental students (83.3\%). (Table 2)

Majority of dental students (63\%) were not aware that basic package of oral care (BPOC) was created by WHO. Basic package of oral care (BPOC) includes oral urgent treatment (OUT), atraumatic restorative treatment (ART) and affordable fluoride toothpaste (AFT) was correctly answered by only $21(8 \%)$ dental students. Surprisingly, most of the dental students (59.5\%) were not aware that primary health care strategy includes equity, prevention, community participation, appropriate technology and intersectorial approach. Only $88(33.3 \%)$ of the surveyed students could correctly identify FDI when asked, "Name the world's main dental/oral health NGO [whose] mandate is to bring together the world of dentistry, represent the dental profession of the world, and stimulate and facilitate the exchange of information across all borders with the aim of optimal oral health for all people." Most of the dental students $\{255(96.6 \%)\}$ affirmed the need for a global oral health course. (Table 2)

Knowledge and attitude scores were calcu-

Table 1. Distribution of dental students according to gender and class.

\begin{tabular}{lccccc}
\hline Gender & Third year & Final year & Interns & Post graduates \\
\hline Male & $23(26.7 \%)$ & $30(39 \%)$ & $36(48 \%)$ & $17(65.3 \%)$ & $106(40 \%)$ \\
Female & $63(63.3 \%)$ & $47(61 \%)$ & $39(52 \%)$ & $9(34.7 \%)$ & $158(59.8 \%)$ \\
Total & $86(32.5 \%)$ & $77(29.2 \%)$ & $75(28.4 \%)$ & $26(9.8 \%)$ & $264(100 \%)$ \\
\hline
\end{tabular}


Table 2. Global oral health information questionnaire.

\begin{tabular}{|c|c|c|c|}
\hline Question & Response & Number & Percentage \\
\hline \multirow{2}{*}{$\begin{array}{l}\text { Q1. Would you volunteer as a dentist in an international setting or } \\
\text { other developing country? }\end{array}$} & Yes & 222 & 84,1 \\
\hline & No & 42 & 15,9 \\
\hline \multirow{2}{*}{ Q2. Do you know the global oral health status? } & Yes & 2 & 0,8 \\
\hline & No & 262 & 99,2 \\
\hline \multirow{2}{*}{$\begin{array}{l}\text { Q3. Are you aware about oral health care systems of developed } \\
\text { and developing countries? }\end{array}$} & Yes & 2 & 0,8 \\
\hline & No & 262 & 99,2 \\
\hline \multirow{2}{*}{ Q4. Have you been trained to serve the underserved population? } & Yes & 85 & 32,1 \\
\hline & No & 179 & 67,9 \\
\hline \multirow{2}{*}{$\begin{array}{l}\text { Q5. Have you been trained for cultural competence in addressing in- } \\
\text { ternational oral health issues? }\end{array}$} & Yes & 0 & 100 \\
\hline & No & 264 & 0 \\
\hline \multirow{2}{*}{ Q6. Are you aware about global health ethics? } & Yes & 79 & 29,9 \\
\hline & No & 185 & 70,1 \\
\hline \multirow{3}{*}{$\begin{array}{l}\text { Q7. Global oral health status information is essential to address in- } \\
\text { ternational health issues? }\end{array}$} & Yes & 194 & 73,5 \\
\hline & No & 7 & 2,7 \\
\hline & Don't Know & 63 & 23,9 \\
\hline \multirow{3}{*}{$\begin{array}{l}\text { Q8. Information about oral health care systems in developed and } \\
\text { developing world is essential to address global oral health issues? }\end{array}$} & Yes & 209 & 79,2 \\
\hline & No & 13 & 4,9 \\
\hline & Don't Know & 42 & 15,9 \\
\hline \multirow{3}{*}{$\begin{array}{l}\text { Q9. Training to serve underserved population is essential to } \\
\text { address global oral health issues? }\end{array}$} & Yes & 209 & 79,2 \\
\hline & No & 15 & 5,7 \\
\hline & Don't Know & 40 & 15,2 \\
\hline \multirow{3}{*}{$\begin{array}{l}\text { Q10. Training in cultural competence is essential to address } \\
\text { global oral health issues? }\end{array}$} & Yes & 219 & 83 \\
\hline & No & 10 & 3,8 \\
\hline & Don't Know & 35 & 13,3 \\
\hline \multirow{3}{*}{$\begin{array}{l}\text { Q11. Awareness about global health ethics is essential to address } \\
\text { international oral health issues? }\end{array}$} & Yes & 220 & 83,3 \\
\hline & No & 13 & 4,9 \\
\hline & Don't Know & 31 & 11,7 \\
\hline Question & Response & Number & Percentage \\
\hline \multirow{4}{*}{ Q12.Who created Basic Package of Oral Care (BPOC)? } & $\mathrm{DCl}$ & 73 & 27,6 \\
\hline & WHO & 71 & 27 \\
\hline & FDI & 57 & 21,6 \\
\hline & Don't Know & 63 & 23,8 \\
\hline \multirow{3}{*}{$\begin{array}{l}\text { Q13. BPOC includes: a) Oral treatment, b) Oral urgent treatment, cl } \\
\text { Pit \& fissure sealants, d) ART, e) Affordable fluoride tooth paste f) } \\
\text { Affordable tooth brush }\end{array}$} & Correct reply & 21 & 8 \\
\hline & Incorrect reply & 152 & 57,6 \\
\hline & Don't Know & 91 & 34,4 \\
\hline \multirow{3}{*}{$\begin{array}{l}\text { Q14. Primary health care strategy includes: a)Equity, b)Prevention c) } \\
\text { Community participation, d)Appropriate technology, e) Intersectorial } \\
\text { approach }\end{array}$} & Correct reply & 107 & 40,5 \\
\hline & Incorrect reply & 111 & 42 \\
\hline & Don't Know & 46 & 17,4 \\
\hline \multirow{4}{*}{$\begin{array}{l}\text { Q15. Which among the following is the world's main } \\
\text { dental / oral health NGO? }\end{array}$} & FDI & 88 & 33,3 \\
\hline & WHO & 121 & 45,8 \\
\hline & IDA & 33 & 12,5 \\
\hline & Don't Know & 22 & 8,3 \\
\hline \multirow{2}{*}{$\begin{array}{l}\text { Q16. Is there a need for global oral health course among dental } \\
\text { students? }\end{array}$} & Yes & 255 & 96,6 \\
\hline & No & 9 & 3,4 \\
\hline
\end{tabular}


lated separately. Each correct response added a score of 1. Mean knowledge scores for third year, final year, interns and residents were 2.06 (1.39), 2.38 (1.17), 2.86 (1.0) and 3.73 (1.35) respectively. Mean attitude scores for third year, final year, interns and residents were 3.82 (0.91), 4.28 (1.26), 4.36 (1.39) and 4.60 (1.17) respectively. Significant differences between the groups were noted for means of knowledge $(\leqslant 0.01)$ and attitude scores $(P \leqslant .05)$. The overall mean score for knowledge and attitude for dental students were 2.75 (1.22) and 4.26 (1.18). (Table 3)

Among the third year students, only $10(11.6 \%)$ students were aware that WHO created the BPOC. Significant differences were noted between the various groups. $(P \leqslant .05)$. Only $21(7.9 \%)$ students could answer correctly the components of BPOC as OUT, ART, AFT; majority being the post graduates/residents (38.4\%). Significant differences were noted between the various groups. $(P \leqslant .01)$. Components of preventive oral health care strategy (POHC) were correctly stated by $17.4 \%, 27.3 \%$, $64 \%$ and $88 \%$ of the third year, final year, interns and postgraduate dental students (residents) respectively with significant differences between the various groups. ( $P \leqslant .01)$.

\section{DISCUSSION}

The delivery of health care services in any country is dependent on a trained cadre of health care professionals. The well-documented global shortage of health care providers, including oral health care providers disproportionately impacts emerging economies and the least developed countries. Faced with serious resource constraints, as well as an immense burden of disease, developing countries are faced with enormous need in the oral health care sector, but, have limited capacity to educate and support the workforce needed to meet these needs. As a result, not enough oral health care professionals are trained; few are offered the opportunity for continuing professional education and growth, and most work in isolation with little chance to learn from colleagues. ${ }^{17}$

Dental education has focused mainly on restorative clinical approaches for individual paying clients while prevention of oral disease in communities or vulnerable populations is given less prominence. Therefore it is an unrealistic expectation for a dental professional to consciously provide care for the underserved populations when formal dental training largely promotes principles of care that are to the contrary. ${ }^{16}$

In the present study, conducted in Central India, eighty seven percent of the surveyed students (222) stated that they would consider volunteering their dental skills as a future dentist in international setting. This was similar to a study conducted at a North American dental school where $84 \%$ students gave similar consents. ${ }^{16}$ Majority of the students in the present study were not aware about the global oral health status (99.2\%), were unaware about oral health care systems being practiced in the industrialized and emerging economies (99.2\%), had not been trained to serve the underserved population $(68 \%)$, had not been trained in global health ethics $(70.1 \%)$ and none of the students had been trained for cultural competence in addressing international oral health issues (100\%). Most of the dental students, were not aware, that WHO created basic package of oral care (63\%), and also, about its components (92\%), about the primary health care strategy $(59.5 \%)$ and about the role and function of FDI (66.7\%). Only $10(11.6 \%)$ of third year students were aware that WHO created the BPOC. Two (2.3\%) students could answer correctly the components of BPOC as OUT, ART, AFT and about the role and functions of FDI. Similarly, in North American school, none of the third year dental students could answer correctly that BPOC was created by WHO nor about the components of BPOC. None were able to identify FDI when asked about its role and function. The mean knowledge and attitude score increases gradually from the

Table 3. Knowledge and Attitude scores of dental students towards global oral health issues.

\begin{tabular}{lcc}
\hline \multicolumn{1}{c}{ Groups } & Knowledge Mean (SD) & Attitude Mean (SD) \\
\hline Third year & $2.06(1.39)$ & $3.82(0.91)$ \\
Final year & $2.38(1.17)$ & $4.28(1.26)$ \\
Interns & $2.86(1.0)$ & $4.36(1.39)$ \\
Post graduates / Residents & $3.73(1.35)$ & $4.60(1.17)$ \\
Total & $2.75(1.22)$ & $4.26(1.18)$ \\
P Value & $\leqslant 0.01$ & $\leqslant 0.05$ \\
\hline
\end{tabular}

$* \leqslant .05, * * \leqslant .01$

(Maximum score: Knowledge: 9, Attitude: 5 ) 
third year group to the residents. The noted differences between student groups could be attributed to more of exposure to dental subject, specifically dental public health text books.

Majority of the dental students (96.6\%) affirmed the need for a global oral health course. Creating a predoctoral global oral health course that includes the principles of $\mathrm{POHC}$ and $\mathrm{BPOC}$, at all levels could reinforce the concept that care to the underserved is integral to the profession-i.e., it is an ethical responsibility. Essentially, it affords students the opportunity to hear, learn, practice, and evaluates for them the value of such care.

It was in 1971 when American Dental Association first published a directory of programs outlining the need for dental personnel and materials in a number of overseas communities. Since then, the participation by dentists and others in international volunteer dental activities has risen significantly. The dedication of the growing number of volunteers who work in some of the world's most deprived communities is fully supported by the American Dental Association. In this direction, Health Volunteers Overseas (HVO) is a nonprofit organization dedicated to improving the quality of health care in emerging and least developed countries through training and education of local personnel health care providers. It is supported by dues and contributions of interested individuals, corporations, and sponsoring professional associations, including the ADA. HVO is governed by a volunteer board of directors which represents a diverse background of experience and professions. There are more than 185 health care professionals who serve in a variety of leadership positions with HVO providing the framework for managing HVO, extensive portfolio of programs. All HVO volunteers are trained, licensed health care professionals who are screened by similarly skilled program directors to ensure that their skills are appropriate to a particular site. Volunteers work alongside their colleagues in emerging economies and least developed countries, providing new insights and techniques. They introduce new teaching methodologies, update or create teaching curricula and inspire new ways of thinking and problem solving. ${ }^{18}$

University of California, San Francisco currently is running a global oral health program with the goal of improving oral and craniofacial health worldwide. The other objectives for the global oral health program include building, strengthening and coordinating activities in global oral health and developing and supporting programs of excellence in global oral health sciences. These include educational, research and community/public service programs. ${ }^{19}$ Global oral health course for dental practitioners is a 6 hour Spring Semester course run by New York dental school and is intended both to provide and inform about oral health issues and research in emerging economies and least developed countries around the world, and also, to inform students of pathways for private practitioners to become involved in providing oral health care in these nations, usually as short-term volunteers. The format utilizes a series of lectures with accompanying readings, each highlighting a different oral health issue in a given country. ${ }^{20}$ It is the time's need to increase awareness among

Table 4. Awareness of dental students towards Basic package of oral care (BPOC) and Primary oral health care strategies.

\begin{tabular}{|c|c|c|c|}
\hline Question & Batch & Correct response & $P$ Value \\
\hline \multirow{5}{*}{$\begin{array}{l}\text { Who created Basic Package of Oral Care } \\
\text { (BPOC)? }\end{array}$} & Third year & $10(3.78 \%)$ & \multirow{5}{*}{$\leqslant 0.05$} \\
\hline & Final year & $21(5.76 \%)$ & \\
\hline & Interns & $27(10.2 \%)$ & \\
\hline & Post graduates/Residents & $13(4.92 \%)$ & \\
\hline & Total & 71 & \\
\hline \multirow{5}{*}{$\begin{array}{l}\text { BPOC includes: al Oral treatment, b) Oral ur- } \\
\text { gent treatment, cl Pit \& fissure sealants, d) } \\
\text { ART, el Affordable fluoride tooth paste f) Af- } \\
\text { fordable tooth brush }\end{array}$} & Third year & $2(2.32 \%)$ & \multirow{5}{*}{$\leqslant 0.01$} \\
\hline & Final year & $5(6.5 \%)$ & \\
\hline & Interns & $4(5.34 \%)$ & \\
\hline & Post graduates/Residents & $10(38.4 \%)$ & \\
\hline & Total & 21 & \\
\hline \multirow{5}{*}{$\begin{array}{l}\text { Primary health care strategy includes: a)Eq- } \\
\text { uity, bJPrevention cl Community participation, } \\
\text { d)Appropriate technology, el Intersectorial ap- } \\
\text { proach }\end{array}$} & Third year & $15(17.4 \%)$ & \multirow{5}{*}{$\leqslant 0.01$} \\
\hline & Final year & $21(27.3 \%)$ & \\
\hline & Interns & $48(64 \%)$ & \\
\hline & Post graduates/Residents & $23(88 \%)$ & \\
\hline & Total & 107 & \\
\hline
\end{tabular}


dental students towards global oral health care delivery systems, health care planning, financing and health care priorities. Applying the best practice principles in global oral health helps to ensure the maximum beneficial impact on any global oral health endeavor.

We would propose a development of systematic curricula for global oral health course in dental schools both in industrialized and emerging economies. The curriculum elements could include global burden of oral diseases, oral health care delivery systems of industrialized and emerging economies, global health ethics, cultural competence in addressing international health issues and the role and functions of WHO, FDI and non dentists. Oral hygiene should be promoted in campaigns supported by governments, industry, health professionals and the non dentists. Creating a healthy oral health policy by incorporating the elements of global health care can be used to argue for increased national support and oral health promotion.

\section{CONCLUSION}

Summarizing the results of this study, these findings indicate a need for global oral health course among dental students in central India. The results suggest that there is a gap between global oral health policy interventions set out by WHO and FDI and awareness of this policy, interventions, and global oral health issues among dental students in central India. The majority of students expressed a desire to volunteer their professional services in international settings. However few students knew about WHO's basic package for oral health care or FDI'S role in global oral health. Creating a predoctoral global oral health course at all levels could reinforce the concept that care to the underserved is integral to the profession.

\section{REFERENCES}

1. Williams DM. Oral health inequalities. JDR 2011;90:549551

2. Pitts N, Amaechi B, Niederman R, Acevedo A-M, and Vianna R, Ganss C. Global oral health inequalities: dental caries task group-research agenda. Adv Dent Res 2011;23:211220.

3. Pihlström BL, Michalowicz BS, Johnson NW. Periodontal diseases. Lancet 2005;366:1809-1820.

4. Petersen PE, Kwan S. The 7th WHO Global Conference on Health Promotion - towards integration of oral health. Community Dent Health 2010;27(Suppl 1):1:1-11.
5. Jin LJ, Armitage GC, Klinge B, Lang NP, Tonetti M, Williams RC. Global oral health inequalities: task group-periodontal disease. Adv Dent Res 2011;23:221-226.

6. Johnson NW, Warnakulasuriya S, Gupta PC, Dimba E, Chindia $M$, Otoh EC. Global inequalities in incidence and outcomes for oral cancer: causes and solutions. Adv Dent Res 2011;23:237-246.

7. Challacombe SJ, Chidzonga M, Glick M, Hodgson T, Magalhães $M$, Shiboski $C$. Global oral health inequalities: task group-challenges and approaches. Adv Dent Res 2011;23:227-236.

8. Marmot M and Bell R. Social determinants and dental health. Adv Dent Res 2011;23:201-206.

9. Williams D. Global uncertainty and global challenges. $J$ Dent Res 2009;88:393-394.

10. Garcia I and Tabak LA Global oral health inequalities: the view from a research funder. Adv Dent Res 2011;23:207-210.

11. Hobdell M, Petersen PE, Clarkson J, Johnson N. Global goals for oral health 2020. Int Dent $J$ 2003;53:285-288.

12. Salama P, Spiegel P, Talley $L$ and Waldman R. Lessons learned from complex emergencies over past decade. Lancet 2004;364:1801-1813.

13. Benzian H and Gelbier S. Dental aid organizations: baseline data about their reality today. Int Dent $J$ 2002;52:309314.

14. American Dental Education Association. Competencies for the new general dentist las approved by the 2008 ADEA House of Delegates). J Dent Educ 2008;72:823-826.

15. Sivapathasundharam B. Dental education in India. Indian $J$ Dent Res 2007;18:93.

16. Karim A, Mascarenhas AK, Dharamsi S. A Global Oral Health Course: Isn't It Time? J Dent Educ 2008;72:12381246.

17. World Health Organization. World Health Report, 2006. Available from: http://www.who.int/whr/2006/whr06_en.pdf

18. American Dental Association. International Dental Volunteer Organization - Profile for Health Volunteers Overseas (HVO). Available from: http://internationalvolunteer.ada.org/organizations

19. Global Oral Health. University of California, San Francisco. Available from: http://dentistry.ucsf.edu/science-research/ global-oral-health

20. Global Oral Health Issues for Dental Practitioners. New York University, College of Dentistry. Available from: http:// www.nyu.edu/dental/bulletin/deptepidem.html 